\title{
Subcellular Fractionation of Tetrahymena pyriformis ST by Zonal Centrifugation: Changes in Activities and Distribution of Enzymes during the Growth Cycle and on Starvation
}

\author{
By D. LLOYD, R. BRIGHTWELL, * SUSAN E. VENABLES, \\ G. I. ROACH AND G. TURNER \\ Medical Research Council Group for Microbial Structure and Function, \\ Department of Microbiology, University College, Newport Road, Cardiff, CF2 ITA
}

(Accepted for publication 17 December 1970)

\begin{abstract}
SUMMARY
Subcellular fractionation of the ciliate protozoon Tetrahymena pyriformis has been carried out using sucrose density gradients in zonal rotors. Fractions containing mitochondria, peroxisomes, 'microsomes' and organelles containing acid hydrolases have been characterized. Specific activities of acid phosphatase, DNase and $N$-acetyl glucosaminidase in whole homogenates increase during the growth cycle, while those of mitochondrial enzyme systems (succinoxidase and 2-oxoglutarate oxidase) as well as those of NADH- and NADPH-cytochrome $c$ oxidoreductases decrease. Increased sedimentability of DNase and $\mathrm{N}$-acetylglucosaminidase is manifest in homogenates of cells grown for 6 days but the density distributions of the sedimentable portions of these enzymes and also that of acid phosphatase is not altered. Marked changes in density distributions of lysosomal enzymes occur on starvation. Resolution of the heterogeneous lysosomal population into several discrete populations with different enzyme complements has been achieved. No significant alteration of mitochondrial density occurs in the stationary phase of growth or on starvation, whereas the median buoyant density of peroxisomes is increased under both these conditions.
\end{abstract}

\section{INTRODUCTION}

Marked ultrastructural changes occur in the ciliate protozoon Tetrahymena pyriformis, both during the growth cycle of a batch culture and on 'starvation'. Thus the mitochondria change in number, shape and distribution (Elliott \& Bak, I964) particularly during the 'ageing' of cells in the stationary phase and histochemical tests reveal that the ultimate fate of mitochondria is digestion in acid-hydrolase containing vacuoles. A five- to sevenfold increase in the activities per cell of both acid phosphatase and ribonuclease occur during the transition from the exponential phase to the stationary phase of growth (Lazarus \& Scherbaum, 1968).

Starvation in an inorganic medium leads to the formation of autophagic vacuoles, smaller vacuoles containing acid phosphatase and residual bodies containing myelin figures (Levy \& Elliott, I968). The specific activity of acid phosphatase does not alter during starvation process, but that of cathepsin doubles or trebles, although this

* Present address: Department of Further Education (Radio), British Broadcasting Corporation, London W. I. 
increase results from a loss of total cell protein rather than from a net synthesis of enzyme.

Although there have been several investigations (Baudhuin, Müller, Poole \& deDuve, 1965) of the subcellular distribution of enzymes in Tetrahymena pyriformis, no attempt has previously been made to detect changes in localization of enzymes during 'ageing' or starvation, or to correlate changes with altered cytology. Up to $75 \%$ of the five acid hydrolases studied by Müller, Baudhuin \& deDuve (I966) are sedimentable at a force of $250,000 \mathrm{~g}$ and show the latency usually associated with enzymes enclosed by organelle membranes. The lysosomal population is heterogeneous with respect to density and a somewhat bimodal distribution of deoxyribonuclease (DNase) suggests the possibility of two distinct populations. The mitochondria of Tetrahymena pyriformis have a median buoyant density in aqueous sucrose of $\mathrm{r} \cdot 2 \mathrm{I}$, contain about $20 \%$ of the total protein and account for most of the respiratory activity of homogenates, while the peroxisomes contain the bulk of the catalase (Müller, Hogg \& deDuve, I968). Two components of the lysosomal population can be distinguished by differences in sedimentation rate.

In the present study we have achieved good resolution of subcellular organelles by density-gradient zonal centrifugation and characterized the resulting fractions by electron microscopy. Changes in specific activities and in density distributions of marker enzymes for lysosomes (acid hydrolases), mitochondria (succinate-ferricyanide oxidoreductase and $\mathrm{NADH}$-cytochrome $c$ oxidoreductase), peroxisomes (catalase) and 'microsomal' cytochrome $c$ oxidoreductases during the growth cycle and during starvation are also reported. A preliminary account of some of this work has previously been published (Brightwell, Lloyd, Turner \& Venables, I968).

\section{METHODS}

Organism and growth medium. Tetrahymena pyriformis strain ST (kindly supplied by Dr Y. Suyama) was used throughout because, unlike strains T, W and GL, it stores little glycogen and isolated mitochondria did not show the instability of oxidative and phosphorylating activities previous reported for other strains (Eichel, 1954). The organism was maintained in $75 \mathrm{ml}$. growth medium ( $250 \mathrm{ml}$. flasks) at room temperature and was transferred every Io days to fresh medium.

The growth medium contained $2 \%(\mathrm{w} / \mathrm{v})$ proteose peptone (Difco Laboratories, Detroit, Michigan, U.S.A.), $0.1 \%$ (w/v) liver digest (Oxoid Ltd, London) and $0.05 \%$ (w/v) silicone MS antifoam RD (Hopkin \& Williams, Chadwell Heath, Essex). The first two components were dissolved in a quarter of the final volume of distilled water, heated to $120^{\circ}$ for $15 \mathrm{~min}$., cooled and centrifuged at $2000 \mathrm{~g}$ for $20 \mathrm{~min}$. to remove suspended solids. The supernatant fluid was decanted, diluted by adding three volumes of distilled water, the antifoam added and the $\mathrm{pH}$ adjusted to $7 \cdot 2$ with $\mathrm{KOH}$. The medium was then sterilized by autoclaving at $15 \mathrm{lb} / \mathrm{in}^{2}$ for $20 \mathrm{~min}$.

Growth of the organism. Cultures were grown at $29^{\circ}$ under forced aeration through a glass tube without a sparger. There was approximately a $5 \mathrm{~h}$. lag phase on inoculation of fresh growth medium with exponentially growing cells (I day old), and this was followed by a phase of logarithmic growth to give a population of 70,000 to 90,000 cells/ $\mathrm{ml}$. at a rate of $0.44 \mathrm{~h} . .^{-1}$ : the growth rate then became slower and the population finally reached 3 to $5 \times 10^{5}$ cells $/ \mathrm{ml}$. (Fig. I). 
Harvesting and preparation of extracts. The culture (4 1.) was rapidly concentrated to $300 \mathrm{ml}$. using the continuous flow head of the MSE I 8 centrifuge with a 'high efficiency insert' (flow rate about $11 . / \mathrm{min}$.) at $3000 \mathrm{rev} . / \mathrm{min}$. $(600 \mathrm{~g})$ and $5^{\circ}$. The concentrated suspension was centrifuged at $1000 \mathrm{~g}$ for $3 \mathrm{~min}$. and the pellet immediately resuspended

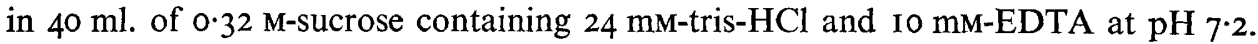
and centrifuged at $1000 \mathrm{~g}$ for $3 \mathrm{~min}$. The organisms were washed and finally resuspended in the same medium at a concentration of $10^{6}$ to $10^{7}$ organisms $/ \mathrm{ml}$. This harvesting procedure caused no apparent damage to organisms in any stage of growth and cell motility was not impaired. If the buffer contains too little EDTA there is aggregation of particles in homogenates, and in mitochondrial fractions from density gradients. Organisms were disrupted using a glass homogenizer (Kontes Glass Company, Vineland, New Jersey, U.S.A.) at $5^{\circ}$. Between ro and 30 gentle up and down strokes were required for about $90 \%$ breakage, which was followed using a microscope. The homogenate was freed of whole organisms and pellicles by centrifugation at $1000 \mathrm{~g}$ for $3 \mathrm{~min}$. and finally contained 3 to $\mathrm{Io} \mathrm{mg}$. $/ \mathrm{ml}$. protein.

Homogenates were fractionated using either the High Speed ' $A$ ' prototype zonal rotor or a BXIV rotor from M.S.E. Ltd, Crawley, Sussex.

The A rotor (Anderson et al. 1966) was loaded at $2000 \mathrm{rev} . / \mathrm{min}$. with a continuous sucrose gradient. Approximately Io $\mathrm{ml}$. of homogenate was then pumped into the centre of the rotor, followed by $10 \mathrm{ml}$. of $10 \%(\mathrm{w} / \mathrm{w})$ sucrose overlay. The rotor was accelerated to $10,000 \mathrm{rev} . / \mathrm{min}$. (5000 $\mathrm{g}$ at the sample zone) for $2 \mathrm{~h}$. and unloaded at $2000 \mathrm{rev} . / \mathrm{min}$. by pumping $60 \%(\mathrm{w} / \mathrm{w})$ sucrose into the periphery of the rotor. Volume of each fraction was $5 \mathrm{ml}$.

The BXIV rotor (Anderson et al. 1967) was loaded with the following volumes of sucrose solutions: $40 \mathrm{ml}$. each of $\mathrm{I} 5,20 \cdot 4,25 \cdot 8,3 \mathrm{I} \cdot 0,36 \cdot 0,4 \mathrm{I} \cdot 0,45^{\circ} 6,50 \cdot 0,54 \cdot 4,58 \cdot 8 \%$; $\mathrm{I} 80 \mathrm{ml}$. $60 \%$; from $\mathrm{I} 0$ to $\mathrm{I} 5 \mathrm{ml}$. cell homogenate, $30 \mathrm{ml}$. each of $9 \%$ and $7 \%$ (all $\mathrm{w} / \mathrm{w})$. Where required, sucrose solutions were buffered at $4^{\circ}$ to $\mathrm{pH} 7.0$ with $10 \mathrm{~mm}$ tris base and $\mathrm{HCl}$. The $\mathrm{B}$ rotor was loaded at $2500 \mathrm{rev} . / \mathrm{min}$., and accelerated to $35,000 \mathrm{rev} . / \mathrm{min}$. for $\mathrm{I} 65 \mathrm{~min}$. $(36,500 \mathrm{~g}$ at sample zone). The rotor was unloaded at $2500 \mathrm{rev} . / \mathrm{min}$. through the flow cell (light path $\mathrm{I} \mathrm{cm}$.) of a Beckman recording spectrophotometer. Light scattering was measured in this system at $520 \mathrm{~nm}$. Fractions ( $10 \mathrm{ml}$.) were collected at $5^{\circ}$. Sucrose concentrations was measured using a refractometer and density calculated from the data of deDuve, Berthet \& Beaufay (I959).

\section{Enzyme assays}

Acid phosphatase (EC 3.I.3.2) activity was assayed by a modification of the method of Torriani ( 1960$)$. The incubation mixture contained enzyme in $8 \mathrm{~mm}-p$ nitrophenyl phosphate, $50 \mathrm{~mm}$-sodium acetate + acetic acid buffer, $\mathrm{pH} 4.2$ and $0.1 \%$ (v/v) Triton X-100. After $20 \mathrm{~min}$. the reaction was stopped and colour developed by the addition of $\mathrm{NaOH}$ to $0.5 \mathrm{M}$. In one experiment $50 \mathrm{~mm}$-sodium $\beta$-glycerophosphate was used as substrate (Müller, Baudhuin \& deDuve, I966).

Acid $N$-acetylglucosaminidase (EC 3.2. I .30) activity was calculated from a similar measurement (Borooah, Leaback \& Walker, 196I) but the reaction mixture contained enyzme in $2.4 \mathrm{mM}$ - $p$-nitrophenyl- $N$-acetyl- $\beta$-D-glucosaminide, I M-NaCl, McIlvaine's citrate-phosphate buffer, $\mathrm{pH}_{4} \cdot 2$ and $0 . \mathrm{I} \%$ (v/v) Triton X-Ioo. After incubation for $20 \mathrm{~min}$. the reaction was stopped and the colour developed by the addition of $2 \mathrm{M}-\mathrm{NH}_{4} \mathrm{OH}-\mathrm{HCl}, \mathrm{pH}$ 10.7. 
Acid DNase (EC 3.I.4.5) activity was calculated from the increase in material with an absorption peak at $260 \mathrm{~nm}$. and soluble in perchloric acid: the assay systems were incubated for $60 \mathrm{~min}$. at $\mathrm{pH} 5.5$ in acetate buffer, as described by Müller et al. (I966). NAD(P)H-cytochrome $c$ oxido-reductases (EC I .6.99.3) were assayed by a modification of the method of Mahler (I955) using mammalian cytochrome $c$ (Sigma type VI) at a final concentration of $0.3 \mathrm{mg} . / \mathrm{ml}$.; under these conditions crude homogenates gave rates of cytochrome reduction measured at $550 \mathrm{~nm}$. equal to those at infinite concentration of electron acceptor. The reaction mixtures also contained (total volume $\mathrm{I} \cdot 0 \mathrm{ml}$.) $0.07 \mathrm{ml}$. of $0.2 \%(\mathrm{w} / \mathrm{v}) \mathrm{NAD}(\mathrm{P}) \mathrm{H}$ and Io mM-KCN (neutralized to $\mathrm{pH} 7 \cdot 2)$ in $\mathrm{K}$-phosphate buffer $(20 \mathrm{~mm})$ at $\mathrm{pH} 7 \cdot 4$. Cyanide was added immediately before enzyme which was used to start the reaction. There was a linear increase in extinction for at least $2 \mathrm{~min}$. The control cuvettes contained reaction mixtures lacking only the nicotinamide nucleotides. Succinate-ferricyanide reductase was followed at $420 \mathrm{~nm}$. under similar conditions of cyanide and buffer concentrations using $6 \mathrm{~mm}$ succinate and I mM-ferricyanide against control cuvettes which lacked succinate. The molar extinction coefficient, $E_{550 \mathrm{~nm}}$. for cytochrome $c$, and $E_{420 \mathrm{~nm}}$ for ferricyanide were taken as $I 8,500$ and 1000 respectively.

Succinoxidase and 2-oxoglutarate oxidase activities of mitochondrial suspensions which had been prepared by the method of Kobayashi (1965) were assayed polarographically (Lloyd \& Brookman, 1967) in a medium containing $0.35 \mathrm{~mm}$-mannitol, $5 \mathrm{mM}-\mathrm{MgCl}_{2}, 10 \mathrm{mM}-\mathrm{KH}_{2} \mathrm{PO}_{4}$ and $0.2 \%(\mathrm{w} / \mathrm{v})$ bovine serum albumin at $\mathrm{pH} 7.2$ at substrate concentration of $6 \mathrm{~mm}$. ADP $(200 \mu \mathrm{M})$ was added routinely in order to obtain the state 3 rate of oxygen uptake (Chance \& Williams, 1955) which may be compared with the oxidative activities of mitochondria from stationary phase cells in which oxidative phosphorylation had become uncoupled from electron transport.

Catalase was assayed spectrophotometrically as described by Lück (1963), except that enzyme activities were calculated from measured initial reaction velocities assuming that $E_{240 \mathrm{~nm}}$. for $\mathrm{H}_{2} \mathrm{O}_{2}=43,600$.

Assays for acid hydrolases were performed at $29^{\circ}$, while those for catalase and oxidoreductases were carried out at room temperature $\left(18^{\circ} \pm 2^{\circ}\right)$ using a Cary model 14 recording spectrophotometer fitted with a o to 0.1 extinction slide wire. Preliminary experiments were carried out with whole homogenates to ensure that the rates of reactions measured were proportional to the amount of homogenate protein used, were not limited by substrate concentration and were linear over the incubation times employed. When assaying fractions, a suitable volume of the most active fraction was used so that the measured reaction volocity was within the range determined for whole homogenate. In a typical experiment, whole homogenate was diluted I in 40 , such that $0.1 \mathrm{ml}$., containing $0.02 \mathrm{mg}$. protein, was used in each assay; $0 . \mathrm{I} \mathrm{ml}$. of the fractions were then found to be suitable volumes of the determination of total amount of enzyme per fraction.

Protein was assayed by the method of Lowry, Rosebrough, Farr \& Randall (I95I) using bovine serum albumin as a standard.

Presentation of Results. Enzyme units are given as nmole of substrate transformed/ min. or measured product formed/min. In Fig. 3 to 6 vertical lines divide the diagrams at density intervals of $0.05 \mathrm{~g} . / \mathrm{ml}$. Percentage sedimentibility is expressed as that proportion of total enzyme units recovered which sedimented beyond $\rho=\mathrm{I} \cdot \mathrm{xO}$ after centrifugation at $6 \times 10^{6} \mathrm{~g}$ min. 


\section{RESULTS}

\section{Changes in specific activities of enzymes during the growth cycle on starvation}

Samples are removed from cultures daily until 7 days after the start of the incubation and homogenates were prepared; progressive loss of viability occurred after this time (Fig. I). The specific activities of succinoxidase and 2-oxoglutarate oxidase (measured using washed mitochondrial suspensions in the presence of $80 \mu \mathrm{M}$-ADP) decreased until after 6 days they were barely detectable. At this stage NADH- and NADPHcytochrome $c$ oxidoreductases were present at $\mathrm{I} 9$ and $39 \%$ of their respective activities in homogenates from 2 day cultures.

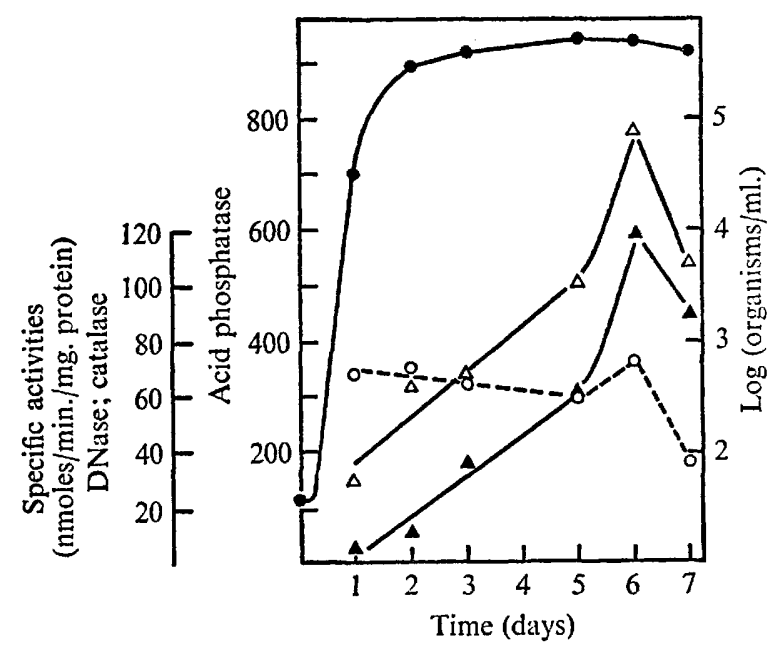

Fig. I

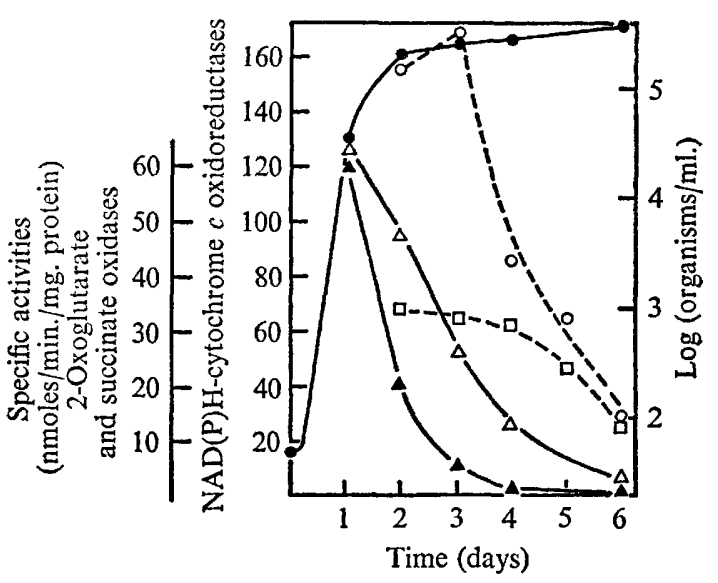

Fig. 2

Fig. $x$. Changes in specific activities of acid phosphatase $(\triangle)$, DNase $(\Delta)$ and catalase $(O)$ of whole homogenates prepared from cells at different times throughout the growth cycle. Growth (๑) measured in terms of organisms $/ \mathrm{ml}$.

Fig. 2. Growth of Tetrahymena pyriformis (๑) and changes in the specific activities of succinate oxidase $(\triangle)$ and 2-oxoglutarate oxidase $(\Delta)$ in mitochondrial suspensions (supplemented with $80 \mu \mathrm{M}-\mathrm{ADP}$ ), and in the NADH- (O) and NADPH- ( $\square$ ) cytochrome $c$ oxidoreductases of whole homogenates.

The specific activities of acid phosphatase and DNase (Fig. 2) and of $N$-acetylglucosaminidase increased during the growth cycle, and at 6 days were five-, I7- and fourfold higher respectively than those at I day. The enzyme activities per cell also increased as previously shown by Lazarus \& Scherbaum (I968) for acid phosphatase and RNase. There were no consistent changes in specific activity of catalase during the growth cycle.

When organisms from a $\mathrm{I}$ day culture were starved for $16 \mathrm{~h}$., the specific activity of catalase increased twofold, while those of acid phosphatase and DNase fell to 42 and $92 \%$ of their values in the growing cells. The specific activities of NADH- and NADPHcytochrome $c$ oxidoreductases had fallen to 70 and $45 \%$ respectively. After $48 \mathrm{~h}$. starvation, the specific activity of catalase had fallen to $95 \%$ of its original value, while that of acid phosphatase was $31 \%$ and DNase showed no further change. 
Fractionation by low-speed zonal centrifugation and electron microscopy of fractions. The fractionation of a homogenate prepared from cells from a 3 day culture is shown in Fig. 3. Succinate-ferricyanide reductase activity (Fig. $3 b$ ) indicates the position of

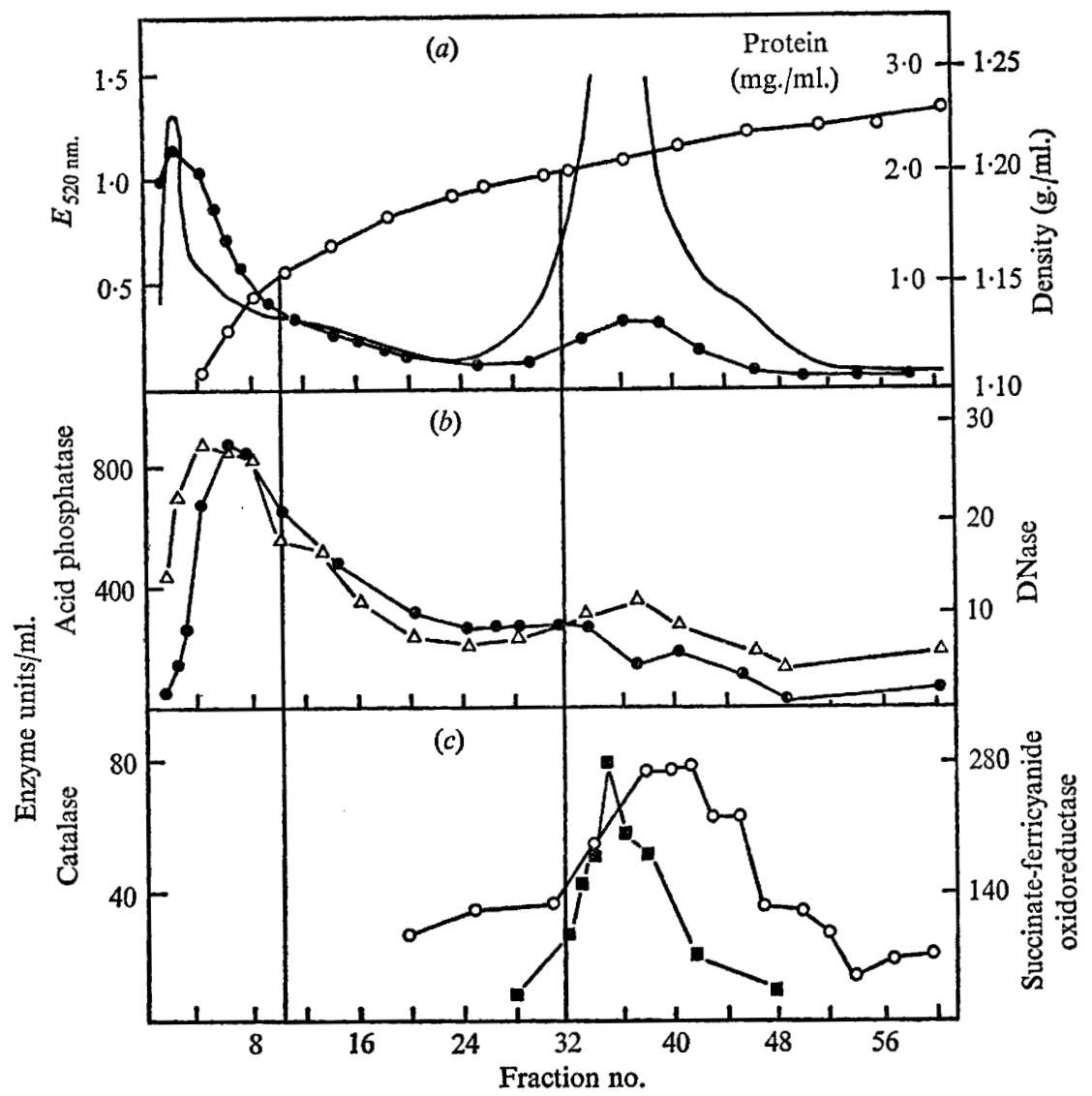

Fig. 3. Homogenate of organisms from a 3 day culture fractionated in type A zonal rotor. The culture was harvested at 150,000 organisms $/ \mathrm{ml}$. The homogenate $(7 \mathrm{ml}$.) contained $70 \mathrm{mg}$. protein. Volume of fractions used in enzyme assays was $0^{\circ} \mathrm{I} \mathrm{ml}$. except for DNase assays (0.5 ml.). (a) Sucrose density gradient (O), protein (O), and light scattering at $520 \mathrm{~nm}$. (solid line). (b) Acid phosphatase $(\bullet)$ and DNase $(\triangle)$. (c) Succinate-ferricyanide oxidoreductase (a) and catalase $(O)$.

mitochondria, which was similar to the peak of sedimentable protein and light scattering (Fig. 3a). This pattern was similar in all other fractionations in this work. The median buoyant density of the mitochondria was $\mathrm{I} \cdot 2 \mathrm{I}$, which was the same as that in fractionation using higher $\boldsymbol{g}$ values indicating that the mitochondria have reached their equilibrium density. There was some separation of mitochondria from peroxisomes, as shown by the distribution of catalase (Müller \& deDuve, 1968), whose median buoyant density $(\mathrm{I} \cdot 22)$ was similar to that in fractionations using higher $g$ forces. Neither fraction was free from acid phosphatase or acid DNase; but the major portions of both these activities were below density $\mathrm{I} \cdot 20$ (Fig. $3 b$ ). The distribution of 
acid phosphatase was the same irrespective of whether $\rho$-nitrophenyl phosphate or $\beta$-glycerophosphate was used as substrate: the former was used in subsequent experiments. Activities of DNase were higher in fractions I, 2 and 3 than those of acid phosphatase, otherwise the distribution were similar.

The latency of acid phosphatase was determined in fractions from a similar experiment. Enzyme preparation was incubated for $15 \mathrm{~min}$. at $0^{\circ}$ in $33 \%$ sucrose and buffer with or without $0.1 \%$ Triton X-I00. Substrate was added in $33 \%$ sucrose and the incubation continued for $15 \mathrm{~min}$. at $0^{\circ}$. In the absence of Triton, the activity of the whole homogenate (hereafter called the 'free activity') was $22 \%$ of the activity in the presence of Triton. In fractions corresponding to numbers 6 and 9 in Fig. 3 the free activity of acid phosphatase was $23 \%$, but it was $73 \%$ in a fraction corresponding to number $3 \mathrm{I}$, which also contained mitochondria. These differences may be related to the lability of the lysosomal membrane, but could also be the result of exposure to different sucrose concentrations in the different fractions before assay.

Electron micrographs of fractions obtained in the experiment shown in Fig. 3 indicated that there were no mitochondria visible in fractions 2 and 12 which had high activities of acid hydrolases. Fraction 2 contained cilia. Fractions 36, 44 and 49 contained mitochondria. Peroxisomes were not seen in these fractions although their presence was indicated by the distribution of catalase: the fixation method used is known to destroy the structure of peroxisomes (M. Müller, personal communication). The outer mitochondrial membranes were intact, and the characteristic tubular form of the cristae was preserved. Despite the high sucrose concentrations these organelles were similar in structure to those observed in the intact organism.

A variety of vacuolar structures were observed in fractions with high activities of acid hydrolases, but no histochemical staining was done to locate enzyme activities.

Some structures visible in sections of whole cells were not observed after fractionation of homogenates. These include macronuclei which do not survive homogenization in the absence of added $\mathrm{Mg}^{2+}$. Rough endoplasmic reticulum which is visible in sections of intact organisms is also destroyed by our procedure, as ribosomes become detached from those membranes in the presence of 10 mM-EDTA. Electron micrographs of whole cells and of various fractions have previously been published (Hughes, Lloyd \& Brightwell, 1970).

\section{Fractionation by high-speed zonal centrifugation}

Mitochondria. Fractionations of homogenates of organisms harvested from a I day culture (Fig. 4), from a 6 day culture (Fig. 5) and from a I day culture afterwards starved for $16 \mathrm{~h}$. (Fig. 6) indicated that the major peaks of light scattering always occurred at density $\mathrm{I} \cdot 2 \mathrm{I}$. These peaks, which corresponded closely with the peaks of sedimentable protein, and succinate-ferricyanide reductase (see above) indicate the position of mitochondria at their isopycnic densities.

Acid hydrolases. The distribution of each of three hydrolases differed after high speed fractionation (Fig. $4 b, 5 b$ and $6 b$ ). Acid phosphatase always showed a higher percentage sedimentability than DNase or $N$-acetylglucosaminidase (Table I). The sedimentable portion of each enzyme was broadly distributed through the gradient, with several peaks, and the ratios of specific activities of the three enzymes assayed was different in each peak. The density distribution of the sedimentable portions of all three enzymes was not markedly different after fractionation of homogenates of 


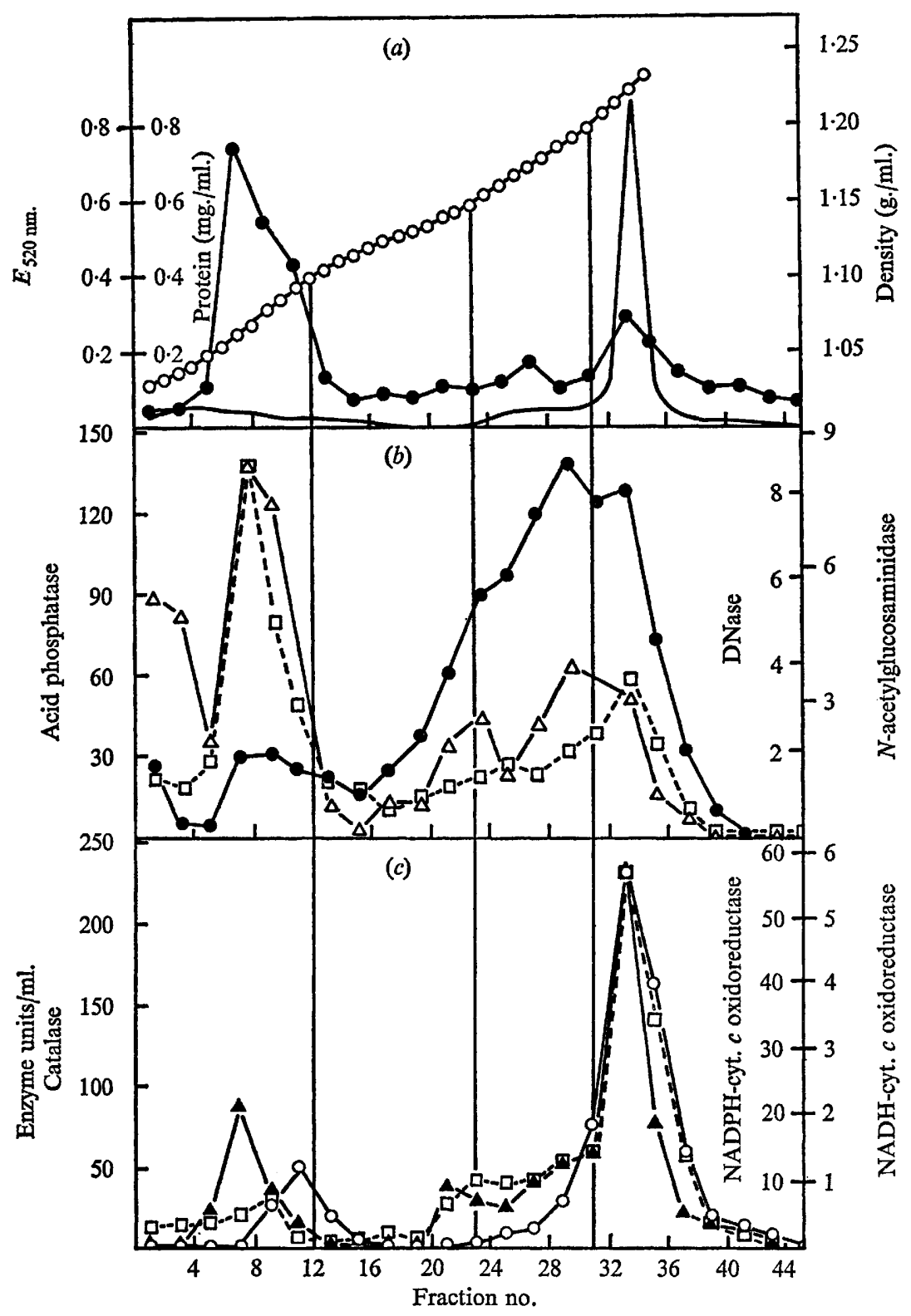

Fig. 4. Homogenate of organisms from a I day culture fractionated in type BXIV zonal rotor. The culture was harvested at 29,000 organisms $/ \mathrm{ml}$. and the homogenate $(7.5 \mathrm{ml}$.) contained $34 \mathrm{mg}$. protein. Whole homogenate was diluted $\mathrm{I}$ in 20 , and volumes of diluted homogenate and of fractions taken for assays were as follows: acid phosphatase, $0.2 \mathrm{ml} ;$ DNase, $0.4 \mathrm{ml}$;; $N$-acetyl- $\beta$-glucosaminadase, $0.5 \mathrm{ml}$; catalase, NADH- and NADPH-cytochrome $c$ oxidoreductases, all O.I ml. (a) Sucrose density gradient $(O)$, protein $(\bullet)$ and light scattering (solid line). (b) Acid phosphatase ( $\bullet$ ), DNase $(\triangle)$, and $N$-acetyl $\beta$-D-glucosaminidase ( $\square$ ). $(c)$ Catalase (O), NADH- $(\square)$ and NADPH- $(\boldsymbol{\Delta})$ cytochrome $c$ oxidoreductases. Figures for recoveries were: protein, $72 \%$; acid phosphatase, $79 \%$; acid DNase, $140 \%$; acid- $N-$ acetyl- $\beta$-D-glucosaminidase, $96 \%$; catalase, $99 \%$; NADH- and NADPH-cytochrome $c$ oxidoreductase, $98 \%$ and $61 \%$ respectively. 


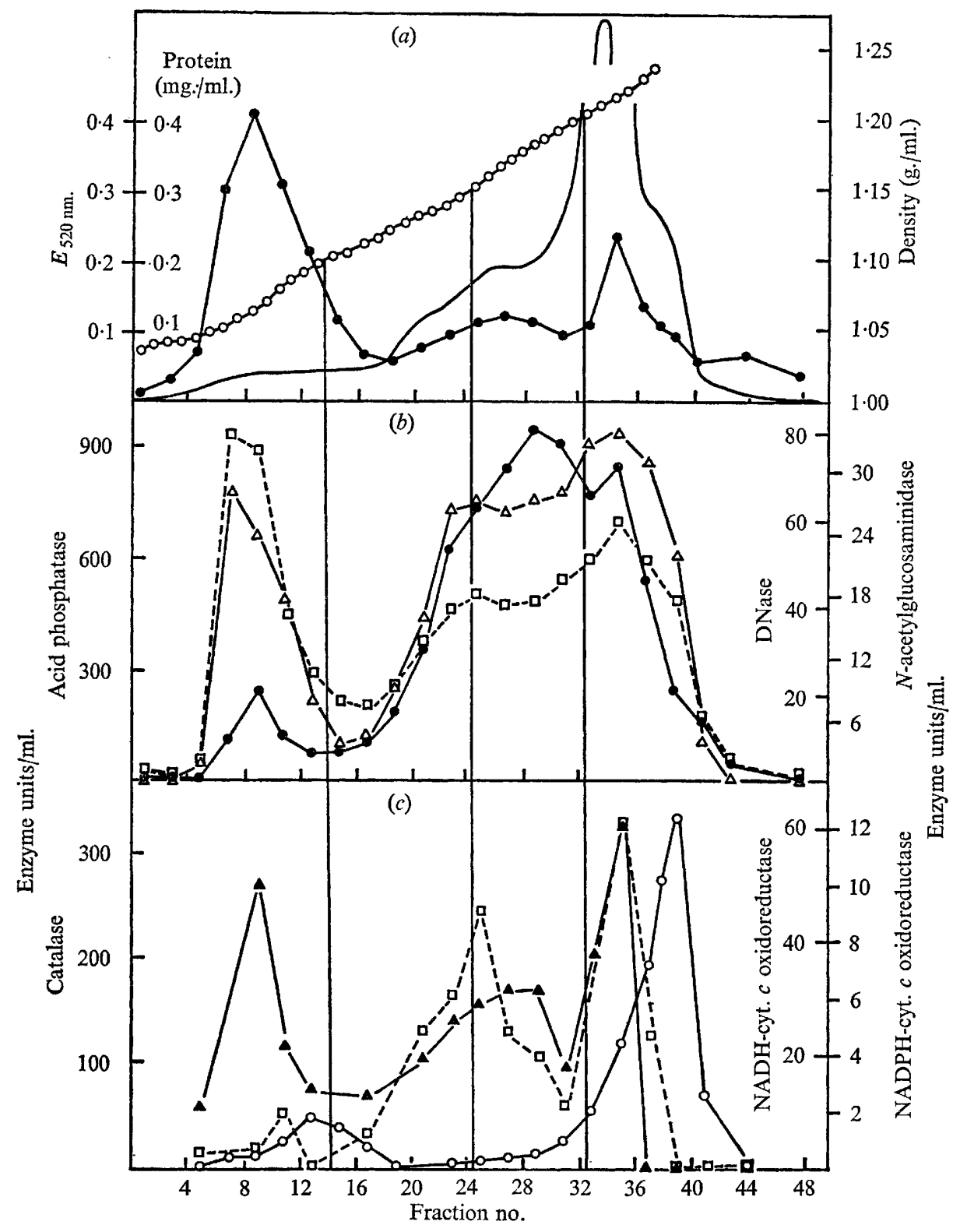

Fig. 5. Homogenate of organisms from a 6 day culture fractionated in type BXIV zonal rotor. The culture was harvested at 440,000 organisms $/ \mathrm{ml}$. and the homogenate (I $2 \mathrm{ml}$.) contained $77 \mathrm{mg}$. protein. Whole homogenate was diluted $\mathrm{I}$ in 40 , and volumes of diluted homogenate and of fractions taken for assays were: acid phosphatase, $0.1 \mathrm{ml}$.; DNase and $N$-acetyl- $\beta$-D-glucosaminidase, $0.2 \mathrm{ml}$; catalase, NADH- and NADPH-cytochrome $c$ oxidoreductases, all o. I ml. (a) Sucrose density gradient (O), protein ( $)$ ) and light scattering (solid line). (b) Acid phosphatase (O), DNase $(\triangle)$, and $N$-acetyl- $\beta$-D-glucosaminidase $(\square)$. (c) Catalase (O), NADH- $(\square)$ and NADPH- ( $\Delta$ ) cytochrome $c$ oxidoreductases. Figures for recoveries were protein, $120 \%$; acid phosphatase, $97 \%$; acid DNase, $150 \%$; acid $N$-acetyl$\beta$-D-glucosaminidase, $95 \%$; catalase, I 10\%; NADH- and NADPH-cytochrome $c$ oxidoreductase, $83 \%$ and $47 \%$ respectivcly. 


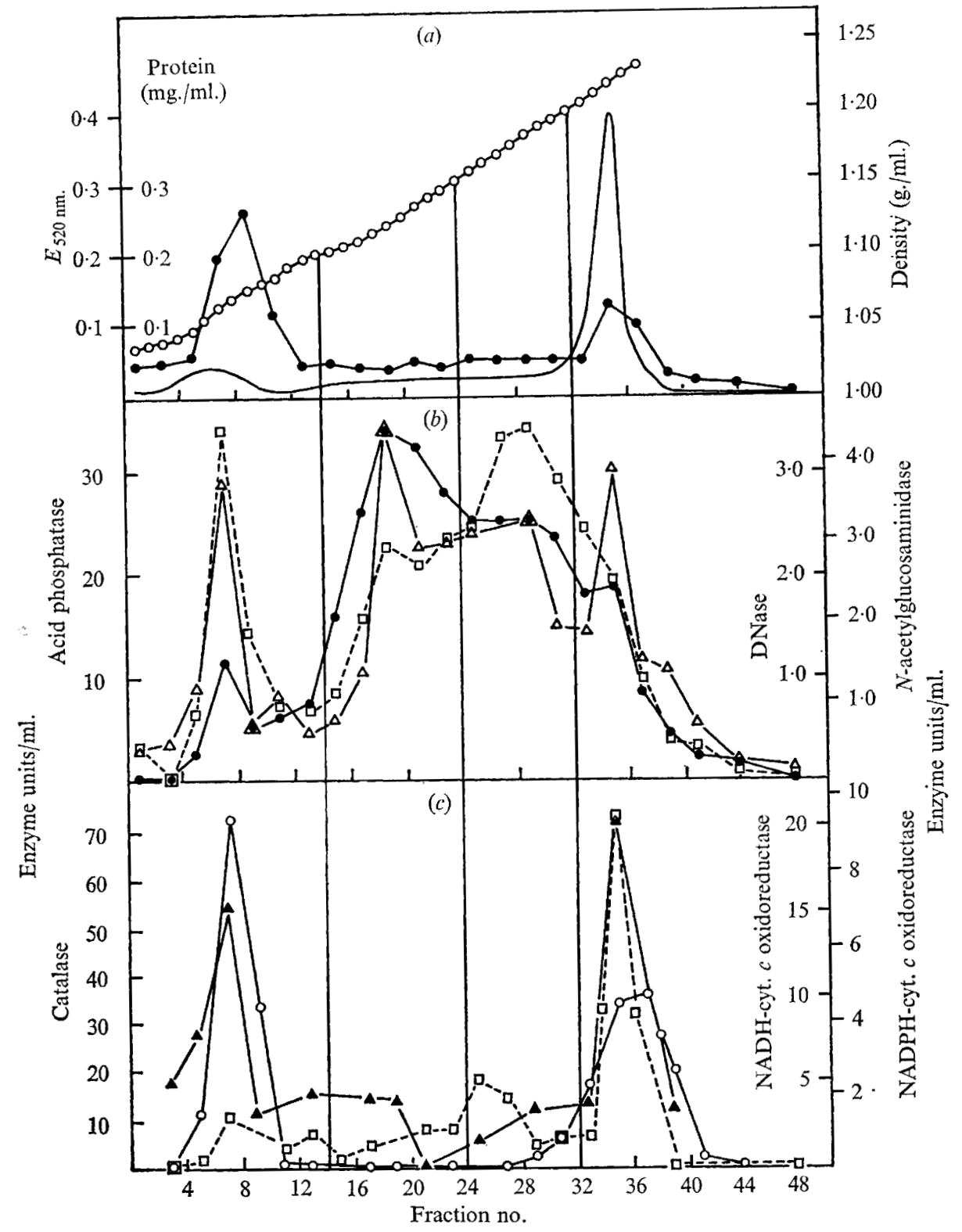

Fig. 6. Homogenate of starved organisms fractionated in type BXIV zonal rotor. The I day culture ( 120,000 organisms $/ \mathrm{ml}$.) was harvested, then washed once and resuspended in a medium containing $10 \mathrm{mM}^{-} \mathrm{KH}_{2} \mathrm{PO}_{4}$, I mM- $\mathrm{MgSO}_{4}$ and $50 \mathrm{mM}-\mathrm{NaCl}$ at $\mathrm{pH} 7 \cdot 2$ (Hamburger \& Zeuthen, 1957). The organisms were maintained with forced aeration in this starvation medium and harvested after $16 \mathrm{~h}$. The homogenate ( $\mathrm{I} \cdot 5 \mathrm{ml}$.) contained $29.5 \mathrm{mg}$. protein. Whole homogenate was diluted $\mathrm{r}$ in 25 , and volumes of diluted homogenate and of fractions taken for assays were: acid phosphatase, $0.2 \mathrm{ml}$; DNase, $0.4 \mathrm{ml}$; $N$-acetyl- $\beta$-D-glucosaminidase, $0.5 \mathrm{ml}$; catalase, $\mathrm{NADH}$ - and NADPH-cytochrome $c$ oxidoreductases, all $0.1 \mathrm{ml}$. (a) Sucrose density gradient $(O)$, protein $(\bullet)$ and light scattering (solid line). (b) Acid phosphatase ( $\odot$ ), DNase $(\triangle)$, and $N$-acetyl- $\beta$-D-glucosaminidase ( $\square$ ). (c) Catalase (O), NADH $(\square)$ and NADPH- $(\Delta)$ cytochrome $c$ oxidoreductases. Figures for enzyme recoveries were: protein, $95 \%$; acid phosphatase, $98 \%$; acid DNase, $150 \%$; acid $N$-acetyl- $\beta$-D-glucosaminidase, $95 \%$; catalase, $102 \%$; NADH- and NADPH-cytochrome $c$ reductase, $52 \%$ and $105 \%$ respectively. 
organisms from I day or 6 day cultures (Fig. 7), but the percentage sedimentability of $N$-acetylglucosaminidase and of DNase was greater in the homogenates of organisms from the stationary phase of growth (Table I).

The distributions of all the three enzymes studied here changed on starving organisms for $16 \mathrm{~h} .:$ there was an increase in the sedimentability of DNase and $N$-acetylglucosaminidase (Table I) and all three distributions have a peak between densities I $\cdot$ IO and I.I5 (Fig. 6b).

Table I. Percentage sedimentabilities and median buoyant densities of the sedimentable portions of enzymes in homogenates of Tetrahymena pyriformis

Percentage sedimentability is expressed as the percentage at total enzyme units recovered sedimenting beyond $\rho=\mathrm{I} \cdot \mathrm{I} O \mathrm{O}$ after centrifugation at $6 \times 10^{6} \mathrm{~g}$ min. Calculations based on the data presented in Fig. 4 to 6.

Sedimentability $(\%)$ and median buoyant density (in parentheses) in homogenates of organisms after growth

Protein

Acid phosphatase

$N$-acetyl- $\beta$-D-glucosaminidase

DNase

Catalase

NADH-cytochrome $c$ oxido-

reductase*

NADPH-cytochrome $c$ oxidoreductase*

$\begin{array}{ccc}\begin{array}{c}\text { I Day } \\ \text { (not starved) }\end{array} & \begin{array}{c}\text { I Day } \\ \text { (and starved I6h.) }\end{array} & \begin{array}{c}6 \text { Days } \\ \text { (not starved) }\end{array} \\ 49 \%(\mathrm{I} \cdot 2 \mathrm{I}) & 5 \mathrm{I} \%(\mathrm{I} \cdot \mathrm{I} 9) & 52 \%(\mathrm{I} \cdot 20) \\ 86 \%(\mathrm{I} \cdot \mathrm{I} 7) & 9 \mathrm{I} \%(\mathrm{I} \cdot \mathrm{I} 6) & 92 \%(\mathrm{I} \cdot \mathrm{I} 8) \\ 48 \%(\mathrm{I} \cdot \mathrm{I}) & 82 \%(\mathrm{I} \cdot \mathrm{I}) & 67 \%(\mathrm{I} \cdot \mathrm{I}) \\ 40 \%(\mathrm{I} \cdot \mathrm{I}) & 80 \%(\mathrm{I} \cdot \mathrm{I}) & 78 \%(\mathrm{I} \cdot \mathrm{I}) \\ 86 \%(\mathrm{I} \cdot 22) & 53 \%(\mathrm{I} \cdot 23) & 89 \%(\mathrm{I} \cdot 23) \\ 88 \%(\mathrm{I} \cdot 2 \mathrm{I}) & 85 \%(\mathrm{I} \cdot 2 \mathrm{I}) & 92 \%(\mathrm{I} \cdot \mathrm{I}) \\ 73 \%(\mathrm{I} \cdot 2 \mathrm{I}) & 67 \%(\mathrm{I} \cdot 22) & 8 \mathrm{I} \%(\mathrm{I} \cdot \mathrm{I})\end{array}$

* Variable recoveries of these enzymes were found due to instability of non-mitochondrial oxidoreductases in extracts.

Catalase. The percentage sedimentability of catalase was similar at I day and at 6 days (Fig. $4 c$ and $5 c$ ) but the median buoyant density of the sedimentable portion was greater at 6 days (Table I). The non-sedimentable catalase moved beyond the nonsedimentable protein in experiments with 1 day and 6 day cultures. However, the proportion of non-sedimentable catalase in starved cells increased and had a similar distribution to that of non-sedimentable protein (Fig. 6c): the median buoyant density of the sedimentable catalase also increased (Table I).

Cytochrome c oxidoreductases. In all three high-speed fractionations the percentage sedimentability of NADH-cytochrome $c$ oxidoreductase was greater than that of the NADPH-linked enzyme (Table I). With regard to the former enzyme the peak of activity which occurred at a density less than I.IO always moved beyond the peak for NADPHcytochrome $c$ oxidoreductase activity in this region of the gradient. The major peaks of both oxidoreductases corresponded to the major peaks of light scattering and therefore to the distribution of mitochondria (Fig. $4 c, 5 c$ and $6 c$ ). Sedimentable peaks of both enzymes occur in the experiment with I day culture between densities I.I4 and $\mathrm{I} \cdot 2 \mathrm{O}$, and the proportion of total enzyme units of both oxidoreductases in this region of the gradient was increased in homogenates of organisms from the 6 day culture; the distribution of each enzyme also changed. In starved organisms there is also an evident difference in the distributions between densities $\mathrm{I} \cdot \mathrm{I} 4$ and $\mathrm{I} \cdot 20$ and only a small 


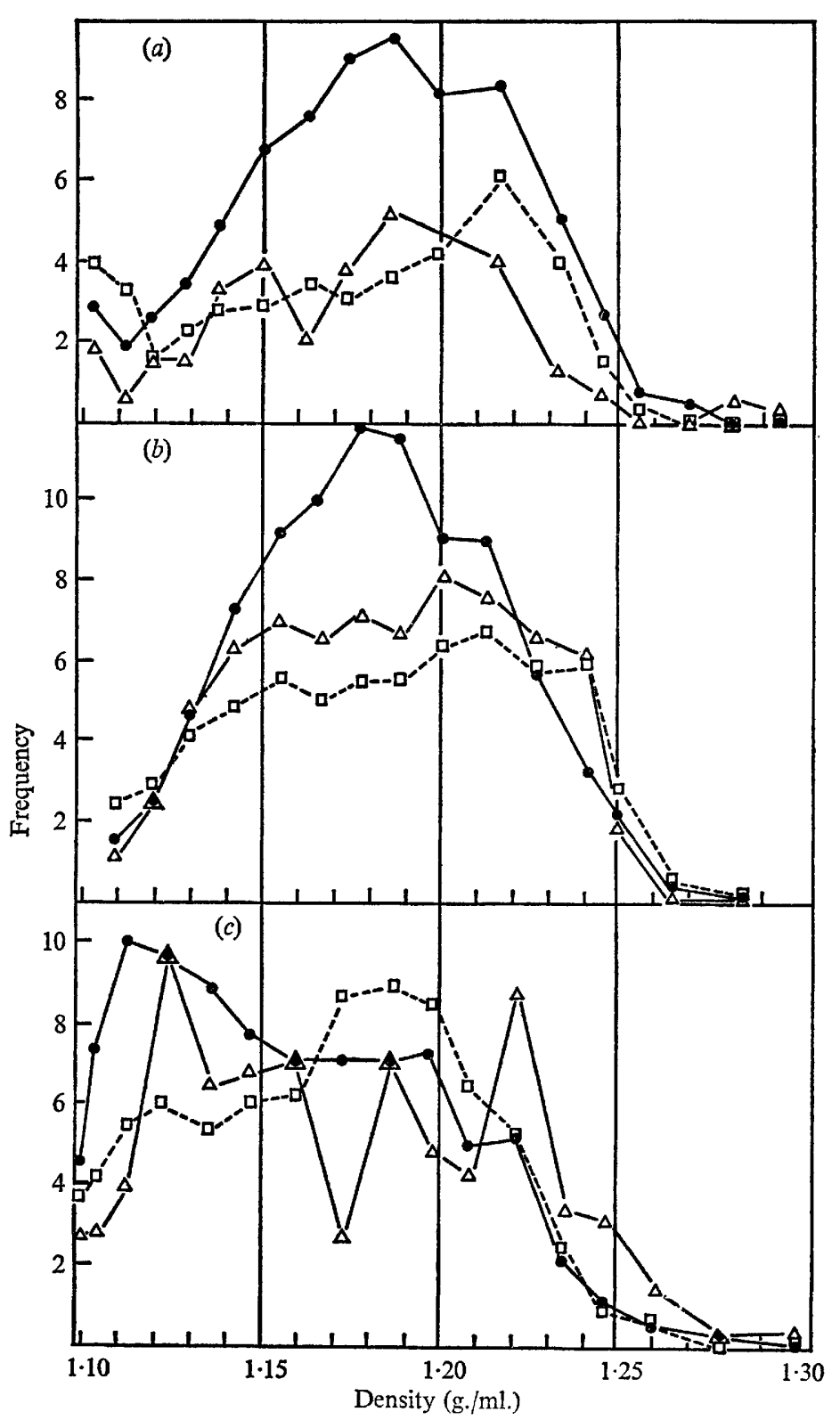

Fig. 7. Frequency distribution plots of sedimentable acid hydrolases in homogenates of organisms from $(a)$ I day culture, $(b) 6$ day culture and $(c)$ I day culture after starvation for I6 h. Data presented in Fig. 4,5 and 6 used to calculate frequencies by the method of deDuve (1967), where

$$
\text { Frequency }=\frac{\text { Enzyme units in a fraction }}{\text { Total enyzme units recovered }} \times \frac{I}{\text { Density increment in that fraction }} .
$$

Acid phosphatase (O), DNase $(\triangle)$ and $N$-acetyl- $\beta$-D-glucosaminidase ( $\square$ ). 
proportion of the total enzyme units is accounted for in this region, as was the case with organisms from the I day culture. There is also, in the starved cells, a peak of NADPH-cytochrome $c$ reductase at density less than $I \cdot I 3$.

\section{DISCUSSION}

The results presented here show that morphological changes observed during the 'ageing' or starvation of Tetrahymena pyriformis (Elliott \& Bak, 1964; Levy \& Elliott, 1968) may also be accompanied by changes of specific activities of marker enzymes. High resolution subcellular fractionation, achieved by zonal centrifugation, shows that these changes need not be linked to changes in distribution of enzymes or to changes in buoyant density of organelles in aqueous sucrose.

The progressive decreases in specific activities of succinoxidase and 2-oxoglutarate oxidase of mitochondria isolated at different phases of the growth cycle of a batch culture (Fig. I) may be due to the accumulation of an inhibitor of electron transport, e.g. a lysophosphatide originating from phospholipids by the action of phospholipases (Eichel, 1960; Thompson, 1967). As the respiratory activities of mitochondria isolated from stain sT are much more stable than those of mitochondria from other strains of Tetrahymena pyriformis, we consider it more likely that this decreased activity reflects the diminishing respiratory rate of the whole organisms as growth rate declines and the stationary phase is attained. The oxidation of both succinate and 2-oxoglutarate by mitochondria from cells from a I day or 2 day culture is tightly coupled to phosphorylation, as indicated by the dependence of oxidation rates on ADP concentration; progressive loss of coupling occurs during the 'ageing' of organisms in the stationary phase of growth. Again this phenomenon could be due to a greater fragility of mitochondria in the stationary phase organisms, the accumulation of an uncoupler, or it may reflect a control mechanism acting in response to a diminished requirement for ATP for cellular syntheses. That the median buoyant density of the mitochondria is not affected suggests that there are no gross changes in protein or lipid composition.

The observations that the specific activities of acid hydrolases increase during the growth cycle and decrease on starvation suggest that the systems here may be used to investigate the control of lysosomal activities.

Increased autophagy has previously been observed in both these situations(Elliott \& Bak, 1964; Levy \& Elliott, I968) but specific activities of enzymes may also be controlled by the rate of hydrolysis of material ingested from the medium under different conditions. Increased autophagy on ageing might be expected to result in changes of lysosomal density; no such changes were observed although starvation led to marked changes in the buoyant density of organelles containing acid hydrolases. In this case the enzyme complements of the different lysosomal populations was apparently altered.

The sedimentability of each of the three acid hydrolases studied was similar in several experiments under the same conditions, despite the variable number of strokes used for homogenization. This suggests that the non-sedimentable portions do not arise from lysosomal breakage. If they are from broken organelles, the ratio of activities of the different enzymes is markedly different from that in the unbroken organelles.

Further work is necessary to correlate possible changes in the structure of endoplasmic reticulum with allocations to the activities and distributions of enzymes. 
Sedimentable non-mitochondrial nicotinamide nucleotide-linked cytochrome $c$ reductases could be suggested as possible marker enzymes of the microsomes of Tetrahymena pyriformis; several of the marker enzymes commonly used in mammalian systems could not be detected, e.g. monoamine oxidase and glucose-6-phosphatase (G. Turner \& D. Lloyd, unpublished results). NADPH-cytochrome $c$ oxidoreductase is not a component of mammalian mitochondria (Parsons, 1966) and its presence in fractions containing mitochondria has been used as an indication of microsomal contamination. However, in Tetrahymena pyriformis the density distribution of this enzyme shows a peak with a median density value of $I \cdot 20$ and this coincides exactly with the distribution of the oxidoreductase which is specific for NADH. We therefore conclude that the NADPH-linked enzyme is genuinely associated with mitochondria and this has been confirmed by observations that the activity of this enzyme cosediments with mitochondria in rate-zonal separations (Turner \& Lloyd, unpublished).

We should like to thank Professor D. E. Hughes for his interest and encouragement, and M.S.E. Ltd for the loan of the High Speed A zonal rotor. R. B. was the holder of an I.C.I. Research Fellowship.

\section{REFERENCES}

Anderson, N. G., Barringer, H. P., Cho, N., Nunley, C. E., Babelay, E. F., Canning, R. E. \& RankIN, C. T. JUn. (I966). The development of low-speed 'A' series zonal rotors. National Cancer Monograph 21, II3-I 36.

Anderson, N. G., Waters, D. A., Fisher, W. D., Cline, G. B., Nunley, C. E., Elrod, L. H. \& RANKIN, C. T. (1967). Analytical techniques for cell fractions. V. Characteristic of the BXIV and BXV zonal centrifuge rotors. Analytical Biochemistry 21, 235-252.

Baudhuin, P., Müller, M., Poole, B. \& DeDuve, C. (1965). Non-mitochondrial oxidizing particles (microbodies) in rat liver and in Tetrahymena pyriformis. Biochemical and Biophysical Research Communications 20, 53-59.

Borroah, J. K., LeABACK, D. H. \& WALKER, P. G. (I96I). Studies on glucosaminidase. II. Substrates for $N$-acetyl $\beta$-glucosaminidase. Biochemical Journal 78, 105-I I0.

Brightwell, R., Lloyd, D., Turner, G. \& Venables, S. E. (1968). Subcellular fractionation of Tetrahymena pyriformis by zonal centrifugation: changes in enzyme distribution during the growth cycle. Biochemical Journal rog, 42p.

Chance, B. \& Williams, G. R. (1955). Respiratory enzymes in oxidative phosphorylation. Journal of Biological Chemistry 2r7, 383-397.

DE Duve, C. (1967). General principles. In Enzyme Cytology, p. I. Edited by D. B. Roodyn. New York: Academic Press.

DE DUVE, C., BeRTHET, J. \& BeAufay, H. (1959). Gradient centrifugation of cell particles. Theory and applications. Progress in Biophysical Chemistry 9, 326-369.

EICHEL, H. J. (I954). Studies on the oxidation of succinic acid by cell-free homogenates of Tetrahymena pyriformis $\mathrm{S}$ and $\mathrm{w}$. Journal of Biological Chemistry 206, I59-167.

EICHEL, H. J. (1960). Electron transport and phosphorylation inhibitor in Tetrahymena and evidence for its formation by a phospholipase. Biochimica et biophysica acta 43, 364-370.

ElliotT, A. M. \& BAK, I. J. (1964). The fate of mitochondria during ageing in Tetrahymena pyriformis. Journal of Cell Biology 20, I13-129.

HAMBURGer, K. \& ZeUthen, E. (1957). Synchronous divisions in Tetrahymena pyriformis as studied in an inorganic medium. Experimental Cell Research 13, 443-45I.

Hughes, D. E., Lloyd, D. \& Brightwell, R. (1970). Structure, function and distribution of organelles in prokaryotic and eukaryotic microbes. Symposia of the Society for General Microbiology 20 , 295-322.

Kobayshi, S. (1965). Preparation and properties of mitochondria from the ciliated protozoon Tetrahymena. Journal of Biochemistry (Tokio) 58, 444-457. 
Lazarus, L. H. \& Scherbaum, O. H. (196I). Activity of ribonuclease, acid phosphatase and phosphodiesterase in Tetrahymena pyriformis during growth. Journal of Cell Biology 36, 415-4I8.

LeVY, M. R. \& Elliott, A. M. (1968). Biochemical and ultrastructure changes in Tetrahymena pyriformis during starvation. Journal of Protozoology 15, 208-222.

Lloyd, D. \& Brookman, J. S. G. (1967). An oxygen electrode reaction vessel. Biotechnology and Bioengineering 9, 271-272.

Lowry, O. H., Rosebrough, N. J., Farr, A. L. \& Randall, R. J. (I95I). Protein measurement with the Folin phenol reagent. Journal of Biological Chemistry 193, 265-275.

LÜcK, H. (1963). Catalase. In Methods of Enzymatic Analysis, p. 885. Edited by H. U. Bergmeyer. New York: Academic Press.

MAHLER, H. R. (1955). DPNH cytochrome $c$ reductase (animal). Methods in Enzymology 2, 688-693.

MülleR, M., Baudhuin, P. \& DEDuve, C. (1966). Lysosomes in Tetrahymena pyriformis. Journal of Cellular Physiology 68, 165-175.

MÜLLER, M., HOGG, J. F. \& DEDUVE, C. (I968). Distribution of tricarboxylic acid cycle and of gloxylate cycle enzymes between mitochondria and peroxisomes in Tetrahymena pyriformis. Journal of Biological Chemistry 243, 5385-5395.

Parsons, D. F. (1966). Ultrastructure and molecular aspects of cell membranes. In Proceedings of the Seventh Canadian Cancer Conference, p. 193. Oxford: Pergamon Press.

Thompson, G. A., JUN. (1967). Studies of membrane formation in Tetrahymena pyriformis. (a) Rate of phospholipid biosynthesis. Biochemistry 6, 2015-202I.

TORRIANI, A. (1960). Influence of inorganic phosphate in the formation of phosphatases by Escherichia coli. Biochimica et biophysica acta 38, 460-468. 